\title{
The dissection theatre of the future is already in routine operation
}

\author{
Franz A Fellner ${ }^{1,2 *}$ \\ ${ }^{1}$ Central Radiology Institute, Kepler University Hospital, Medical Faculty of the Johannes Kepler University, Linz, Austria \\ ${ }^{2}$ Medical Faculty of the Friedrich-Alexander-University of Erlangen-Nürnberg, Erlangen, Germany
}

\begin{abstract}
Introduction: In the meantime, new methods from the digital field are finding their way into anatomy training for medical students. We have now taken a significant innovative step in this regard by showing the three-dimensional anatomy of living human beings using CT and MR data sets in a high-end projection room, the socalled dissection theatre of the future, using a projection surface of $16 \times 9$ meters.

Methods: For this dissection theatre of the future, a separate course "virtual anatomy and pathoanatomy" has been integrated into the existing anatomy curriculum of the Johannes Kepler University in Linz. This course is anchored horizontally and vertically in the 3rd and 4th semesters of medical training. With a recently developed $3 \mathrm{D}$ post-processing method, called cinematic rendering, the students experience the anatomy of living human beings very photorealistically in $3 \mathrm{D}$ using active $3 \mathrm{D}$ shutter glasses.

Results: After a pilot phase, the required image data could be imported into the system without any problems. All courses in the winter semester $2019 / 2020$ were held without any problems. There were no technical failures. The permanent change between $3 \mathrm{D}$ and $2 \mathrm{D}$ presentations during the courses was also possible without any problems. Here, too, there were no technical failures. In the pilot phase and at the end of the first real teaching operation in the winter semester $2019 / 2020$, the course was evaluated by the students. In both cases there were only very good to excellent ratings by the students.
\end{abstract}

Conclusion: With the creation of a regular course "virtual anatomy and pathoanatomy" in the "Dissection Theatre of the Future", a significant step has been taken in the further development of anatomy teaching for medical students.

\section{Introduction}

In 2008 we started to present medical topics from the field of radiology to the public in popular science at the Ars Electronica Center in Linz, Austria, the so-called Museum of the Future. In 2014 we expanded the subject area to include virtual anatomy based on X-ray, computed tomography (CT) and magnetic resonance (MR) imaging examinations.

The so-called "Deep Space" is used for these kind of events. This is a high-tech room for 150 visitors with a 16 by 9 meter wall projection and an additional 16 by 9 meter floor projection. 4 projectors for wall and 4 projectors for floor projection enable laser tracking and stereoscopic 3D projections of the highest quality.

In order to be able to present CT and MR data sets in 3D, we first developed a stereoscopic volume rendering program ourselves for the 3D projection of medical image data in the Deep Space [1]. This made it possible to present virtual anatomy to the public in 3D and a series of events entitled "anatomy for everybody" began, which is still running.

In the meantime we made a significant change in the rendering method used. The so-called "cinematic rendering" has been available for a number of years, a revolutionary new method that enables a photo-realistic three-dimensional display of medical image data on DICOM basis of a previously unknown quality [2]. With the help of its developer, this method was installed in the Deep Space as a 3D stereoscopic prototype and has been used for 3-dimensional virtual anatomy ever since. Navigation through the data sets takes place in real time using a game controller [3]. The viewers wear active 3D shutter glasses and thus have a very realistic three-dimensional impression.

Subsequently, the idea arose to integrate the virtual anatomy with cinematic rendering in the Deep Space of the Ars Electronica Center into the curriculum of anatomy teaching at the Medical Faculty of the Johannes Kepler University in Linz. This was finally implemented in the 2019/2020 winter semester. Thus the project title "dissecting theatre of the future" was created.

\section{Materials and methods}

In the pilot phase of the implementation, a trial lecture Virtual Anatomy using cinematic rendering, albeit non-stereoscopic, was held as part of the regular anatomy training at the University of Erlangen and structurally evaluated [5]. Then the implementation of cinematic rendering in 3D took place in the Deep Space of the Ars Electronica Center in Linz.

${ }^{\star}$ Correspondence to: Franz A. Fellner, Central Radiology Institute, Kepler University Hospital, Medical Faculty of the Johannes Kepler University, Linz, Austria, E-mail: franz.fellner@kepleruniklinikum.at

Key words: education, medical education, health education, anatomy, virtual anatomy, virtual pathoanatomy, cinematic rendering, dissection theatre, computed tomography, magnetic resonance (MR) imaging

Received: January 04, 2021; Accepted: January 29, 2021; Published: February 02,2021 
In the anatomy curriculum of the Medical Faculty of Johannes Kepler University, the anatomy specialization takes place in the 3rd and 4th semesters. For the lectures in the 3rd semester of the 2019/2020 winter semester, 90 minutes of the course "virtual anatomy and pathoanatomy" in the Deep Space of the Ars Electronica Center were fixed per week. In advance, a virtual anatomy curriculum was developed that is strictly parallel to the topics covered in conventional anatomy lessons. This means that the course remains consistently organ and system-centered for the students. The CT and MR data sets required for this were selected from January to September 2019, anonymized, imported into the Deep Space server and prepared for the courses. In addition, Powerpoint presentations with x-ray images, CT and MR images with normal anatomy and pathological changes were created for the courses. This enables an interactive form of teaching in which one can permanently switch between 2D and 3D anatomy in the course. Due to the principle of stereoscopy, the students have to put on active $3 \mathrm{D}$ shutter glasses for the $3 \mathrm{D}$ presentations (Figure 1). The "virtual anatomy and pathoanatomy" was defined as a mandatory course for the students with a system-immanent examination character.
At the end of the semester, the students were asked to carry out a written evaluation of the event via the internal Moodle platform.

\section{Results}

The evaluation of the virtual anatomy lecture with cinematic rendering in $2 \mathrm{D}$ already achieved very good to excellent results with the students.

The implementation of the data for cinematic rendering in 3D in Linz was straightforward. All planned CT and MR data sets could be installed and processed on the cinematic rendering server without any problems.

At the beginning of October 2019, the course "Virtual Anatomy and Pathoanatomy" began in the Deep Space of the Ars Electronica Center. In the third semester, 63 students were enrolled who took part in the event every week. All events could be carried out as planned. Technical problems (e.g. system crashes, projector failures, etc.) never occured. The permanent change between $3 \mathrm{D}$ and $2 \mathrm{D}$ projection was completely problem-free and robust. The number of participants of 63 students enabled interactive lessons with permanent integration of

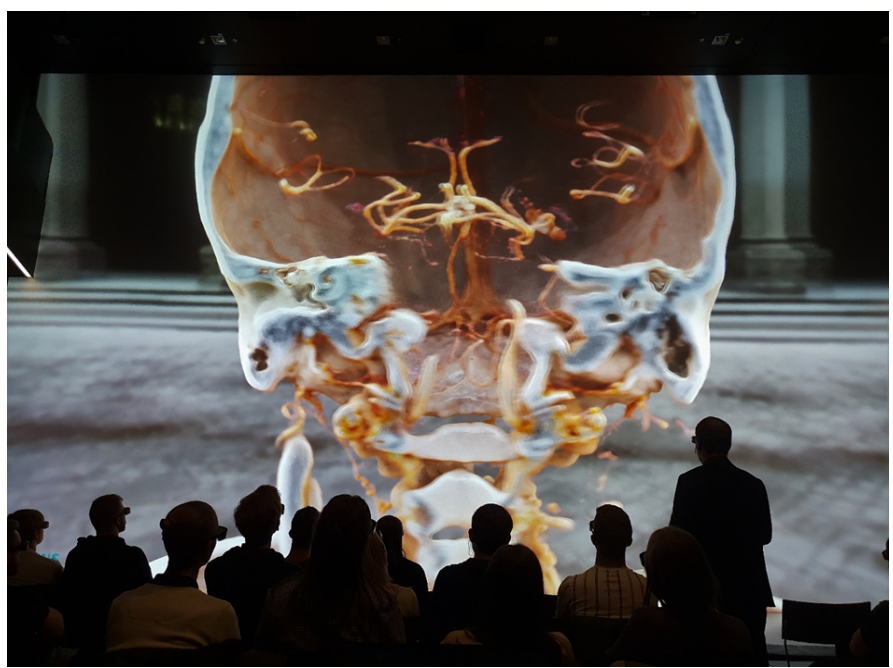

Figure 1. Scene from a course in the track virtual anatomy and pathoanatomy in the dissecting theatre of the future. Due to the principle of stereoscopy, active 3D shutter glasses provide a very realistic 3-dimensional image impression. Without glasses, the image is blurred or has double contours, as can be seen in this example

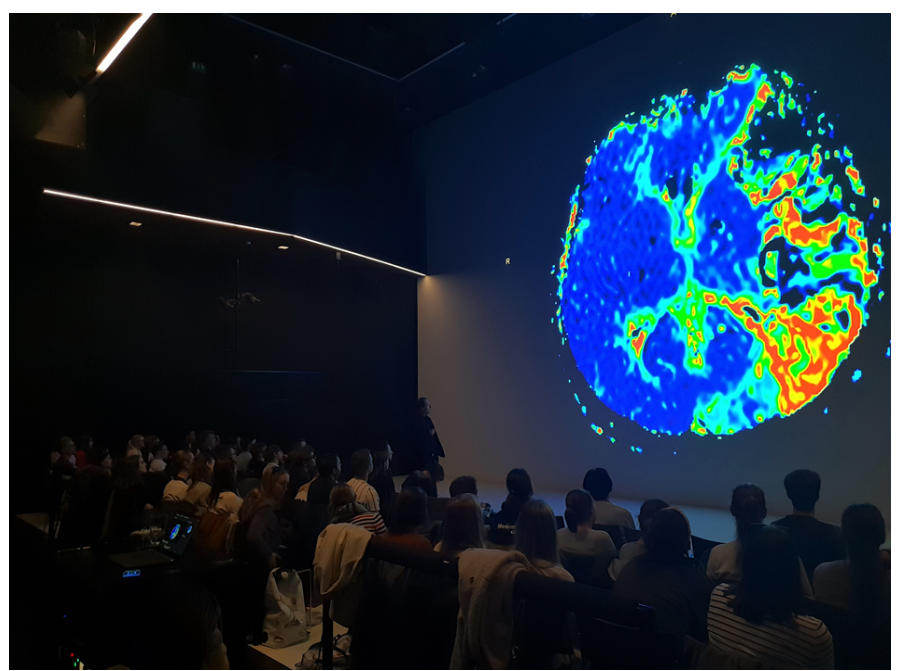

Figure 2. Scene from a course in the track Virtual Anatomy and Patho-Anatomy in the Dissecting Theatre of the Future. The additional demonstration of patho-anatomical changes (as in this middle cerebral artery infarction) facilitates the understanding of the anatomy and increases the compliance of the students to deal intensively with the anatomy 

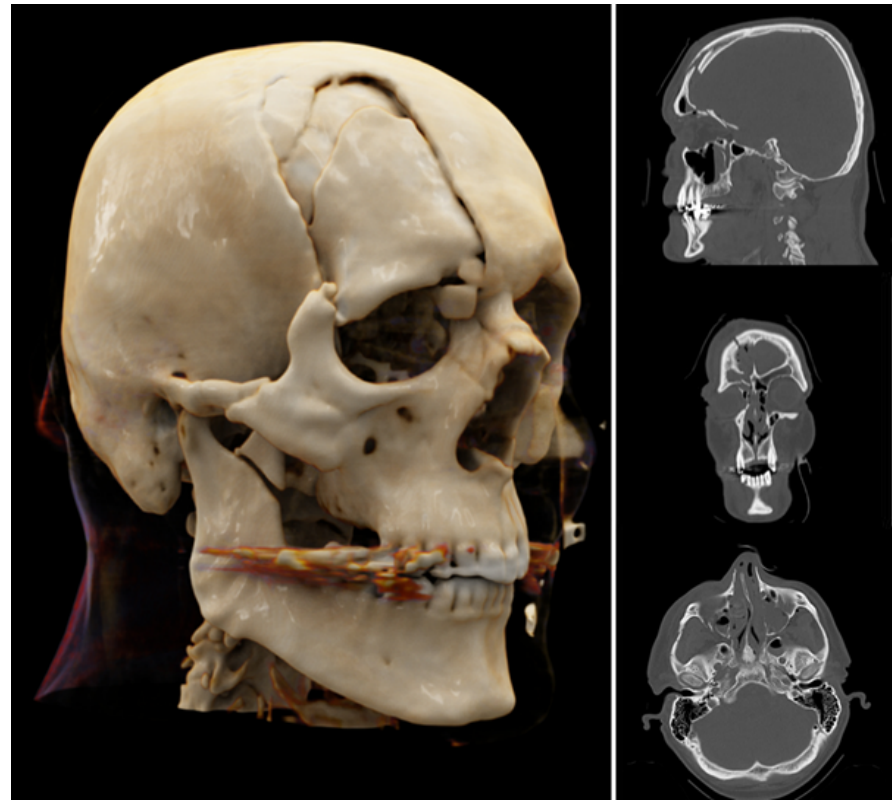

Figure 3. Three-dimensional visualization of the polytrauma CT scan using cinematic rendering in a patient with a skull fracture (from: Firmötz A, Fellner FA (2020) Virtual anatomy and pathoanatomy: Cinematic rendering of a traumatic brain injury. Trauma Emerg Care 5)

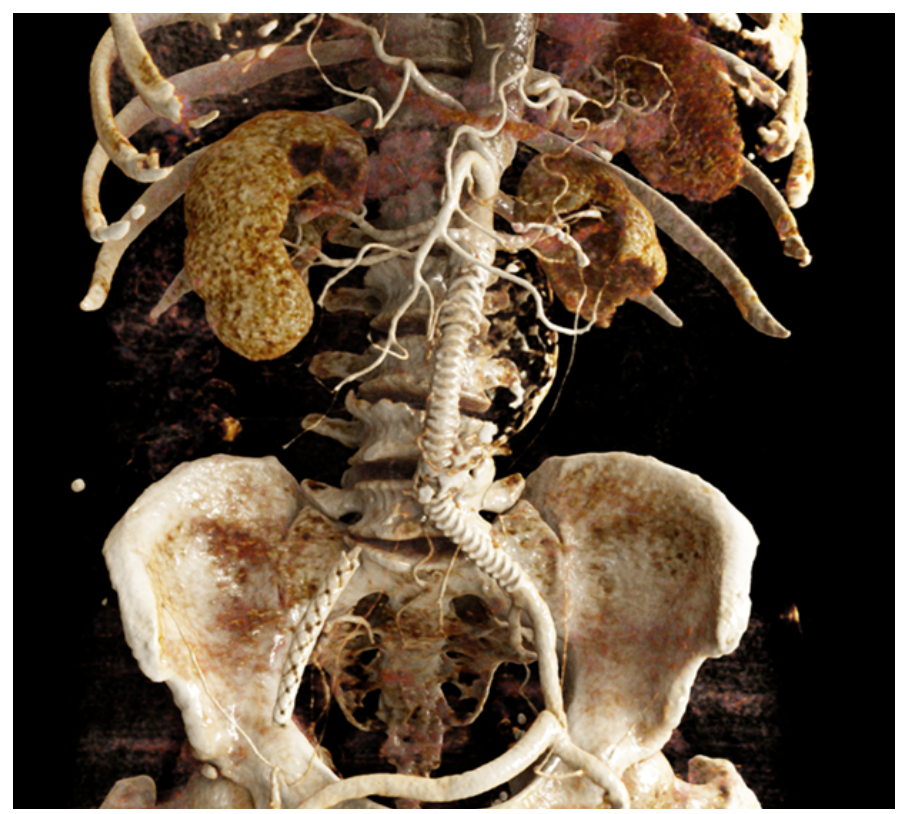

Figure 4. Cinematic Rendering image of an abdominal aortic stent graft and its sidebranches, the coil in the left small calibrated accessory renal artery, and the maintained blood flow in the crossover bypass (from: Hagleitner G, Pichler P, Kiblböck P, Fellner FA (2020) Cinematic rendering in vascular imaging: Abdominal aortic aneurysm (AAA) treated with fenestrated endovascular aortic repair (FEVAR). J Transl Sci 7)

the students through personal queries by the lecturer. Of course, the students could ask questions at any time, which were then addressed in a dedicated manner.

The final evaluation resulted in positive to excellent ratings almost without exception. Many students described the course as the highlight of the semester. Individual students only rated it negatively if the course lasted 135 minutes or longer instead of 90 minutes, which was the case twice in the semester for organizational reasons.

\section{Discussion}

Since its invention, anatomy training based on dissection of cadavers has not developed significantly for centuries in principle [6]. It was not until the 1990s that anatomy training began to move in the sense of further development through the integration of modern methods, such as the use of interactive 3D graphics programs for human anatomy. Another step, which we also took in the 1990s, was the integration of radiological images (x-ray, CT, MR, ultrasound) into conventional anatomy lessons [4]. Since then, these new methods, which can be subsumed under the term virtual anatomy, have become more and more important in terms of mixed learning and are particularly well accepted by students [7-14].

With the creation of a regular course "virtual anatomy and pathoanatomy" in the "dissection theatre oft he future", a significant step forward was taken in this regard. New powerful 3D post-processing methods, such as cinematic rendering, open up new possibilities in the use of radiological image data for anatomy lessons. This adds a new level of anatomy study to living people to conventional cadaver-based anatomy.

The first evaluations have shown that this new method is very well accepted by the students. Another aspect is that medical students are made familiar with the imaging methods of radiology at a very early stage, which will be of great benefit to them in the course of their further studies and their later professional activity. The horizontal and vertical integration of the "virtual anatomy and patho-anatomy" into the anatomy curriculum enables a very high standard in terms of blended learning. The demonstration of pathoanatomical cases (Figure 2) facilitates the recognition and learning of relevant clinical structures in terms of clinical anatomy and increases the compliance of the students to deal intensively with the sometimes very dry subject.

Initial experience has already shown that the cinematic rendering of CT data sets allows excellent visualization of bone and vascular structures, which conventional cadaver-based anatomy cannot achieve in this form [15-24], see Figures 3 and 4. Other structures, such as nerves and fasciae, have not yet been able to be adequately represented using radiological methods. In this regard, the conventional corpsebased anatomy or dedicated 3D computer programs can be used.

\section{Conflicts of interest}

The authors declare that they have no conflicts of interest.

\section{Funding statement} article.

There was no financial support for research and publication of this

\section{References}

1. Fellner FA, Berger F, Fellner C, Kremer C, Hörtner H, et al. (2016) Stereoscopic volume rendering of medical imaging data for the general public. J Health Med Informat 7: 213.

2. Comaniciu D, Engel K, Georgescu B, Mansi T (2016) Shaping the future through innovations: from medical imaging to precision medicine. Med Image Anal 33: 19-26. [Crossref]

3. Fellner FA (2016) Introducing cinematic rendering: A novel technique for postprocessing medical imaging data. J Biomedical Science and Engineering 9: 170-175.

4. Fellner FA, Engel K, Kremer C (2017) Virtual Anatomy: The dissecting theatre of the future - implementation of Cinematic Rendering in a large $8 \mathrm{~K}$ high-resolution projection environment. $J$ Biomedical Science and Engineering 10: 367-375.

5. Binder J, Krautz C, Engel K, Grützmann R, Fellner FA, et al. (2019) Leveraging medical imaging for medical education - A cinematic rendering-featured lecture. Ann Anat 222: 159-165. [Crossref] 
6. Guimarães B, Dourado L, Tsisar S, Diniz JM, Madeira MD, et al. (2017) Rethinking anatomy: How to overcome challenges of medical education's evolution. Acta Med Port 30: $134-140$

7. Moro C, Štromberga Z, Raikos A, Stirling A (2017) The effectiveness of virtual and augmented reality in health sciences and medical anatomy. Anat Sci Educ 10: 549-559

8. Darras KE, Spouge R, Hatala R, Nicolaou S, Hu J, et al. (2019) Integrated virtua and cadaveric dissection laboratories enhance first year medical students' anatomy experience: a pilot study. BMC Med Educ 19: 366. [Crossref]

9. Tam MD (2010) Building virtual models by postprocessing radiology images: A guide for anatomy faculty. Anat Sci Educ 3: 261-266. [Crossref]

10. Darras KE, Forster BB, Spouge R, de Bruin AB, Arnold A, Nicolaou S, et al. (2020) Virtual dissection with clinical radiology cases provides educational value to first year medical students. Acad Radiol 27: 1633-1640.

11. Darras KE, Forster BB, Nicolaou S, Munk PL (2017) A Golden Opportunity for Radiologists: Bringing Clinical Relevance to Undergraduate Anatomy Through Virtual Dissection. Can Assoc Radiol J 68: 232-233.

12. Triepels CPR, Smeets CFA, Notten KJB, Kruitwagen RFPM, Futterer JJ, et al. (2020) Does three-dimensional anatomy improve student understanding? Clin Anat 33: 25-33. [Crossref]

13. Elshafei M, Binder J, Baecker J, Brunner M, Uder M, et al. (2019) Comparison of Cinematic Rendering and Computed Tomography for Speed and Comprehension of Surgical Anatomy. JAMA Surg 154: 738-744. [Crossref]

14. Binder JS, Scholz M, Ellmann S, Uder M, Grützmann R, et al. (2020) Cinematic Rendering in Anatomy: A Crossover Study Comparing a Novel 3D Reconstruction Technique to Conventional Computed Tomography. Anat Sci Educ 2020.
15. Fellner FA, Behawy M (2017) Cinematic and volume rendering of a scaphoid fracture Glob Imaging Insights 2.

16. Hagleitner G, Fellner FA (2017) Ossicle vs. avulsion fracture: Cinematic rendering of MDCT data as an additional diagnostic key. Glob Imaging Insights 2.

17. Asel C, Malek M, Fellner FA (2018) Preoperative cinematic rendering of a sinus frontalis frontal bone fracture. Glob Imaging Insights 3.

18. Firmötz A, Fellner FA (2020) Virtual anatomy and pathoanatomy: Cinematic Rendering of a proximal humerus fracture. Glob Imaging Insights 5.

19. Derler V, Fellner FA (2020) Virtual anatomy and pathoanatomy - subluxation fracture of the cervical spine. Glob Imaging Insights 5.

20. Stehrer R, Malek M, Fellner FA 2020) Cinematic Rendering for virtual anatomy and pathoanatomy in cranio-maxillofacial trauma care. Trauma Emerg Care 5.

21. Firmötz A, Fellner FA (2020) Virtual anatomy and pathoanatomy: Cinematic rendering of a traumatic brain injury. Trauma Emerg Care 5.

22. Hofko M, Sonnberger M, Fellner FA (2020) Cerebral dural arterio-venous fistula - Par I: Virtual anatomy and pathoanatomy in CT and MR imaging. Trauma Emerg Care 5.

23. Hagleitner G, Pichler P, Fellner FA (2020) Understanding vascular pathoanatomy: Cinematic Rendering of an abdominal aortic aneurysm treated with chimney endovascular aortic repair. Glob Imaging Insights 5.

24. Hagleitner G, Pichler P, Kiblböck P, Fellner FA (2020) Cinematic rendering in vascular imaging: Abdominal aortic aneurysm (AAA) treated with fenestrated endovascular aortic repair (FEVAR). $J$ Transl Sci 7.

Copyright: (C2021 Fellner FA. This is an open-access article distributed under the terms of the Creative Commons Attribution License, which permits unrestricted use, distribution, and reproduction in any medium, provided the original author and source are credited. 